Revista de Indias, 1998, vol. LVIII, núm. 212

\title{
DESIGUALDAD Y RACISMO. DEMOGRAFÍA Y SOCIEDAD EN CUBA A FINES DE LA ÉPOCA COLONIAL
}

POR

\author{
PABLO TORNERO
}

Universidad de Sevilla

\begin{abstract}
Estudio de la estructura demográfica y caracterización de la sociedad cubana de finales del siglo XIX, a partir del censo de 1899. En él se trata de demostrar que la fuerte desigualdad social de la sociedad cubana de fines de la época colonial, la dualidad de su entramado social, blancos y negros, es consecuencia de la estructura económica de la isla que tenía su base en la plantación. Este proceso condicionó la integración de la población de color en la sociedad civil cubana, en los primeros años de la república.
\end{abstract}

Al término del dominio español en Cuba, 1898, la sociedad cubana se caracterizaba por la desigualdad social, consecuencia de la estructura económica de la Isla que configuró su tejido productor, basado en el modelo azúcar-esclavitud y que imperó en Cuba hasta bien avanzado el siglo XIX. Ello condujo igualmente a una fuerte desigualdad racial, ya que los blancos dueños de los medios de producción utilizaron durante siglos, mano de obra negra, esclava, a la que nunca se permitió su integración en el entramado de la sociedad civil cubana ${ }^{1}$.

De este modo el colonialismo español, en alianza, con el propio ejercido, en el interior, por la oligarquía criolla, se encargó de crear una sociedad dual, de blancos y negros.

1 INSTITUTO DE HISTORIA DE CUBA. Historia de Cuba. Las luchas por la independencia nacional y las transformaciones estructurales. 1868-1898. Grupo de Redacción: María del Carmen BARCIA, Gloria García y Eduardo Torres CuEvas, La Habana, Editora Política, 1996. 
La trata negrera que llevó a Cuba más de un millón de esclavos, desde el siglo XVI a fines del XIX, a impulsos de un modo de producción que tenía su base en la plantación, desarrolló una sociedad nueva, distinta a la anterior de la conquista y también diferente a la organizada durante los primeros dos siglos de dominación europea. $Y$ es que, en efecto, desde fines del XVIII, una riada de inmigrantes negros, forzados, llegaron a Cuba y este aporte poblacional, junto al también importante flujo migratorio hispano y en menor medida de chinos, creó las condiciones sociales y culturales para la conformación histórica de la realidad cubana ${ }^{2}$.

En 1887 la esclavitud quedó abolida en la Gran Antilla y pocos años después los españoles eran expulsados del territorio cubano. Los negros que habían participado activamente en las guerras libertadoras se incorporaban así a una nación común de blancos y negros ${ }^{3}$.

Sin embargo las condiciones en que la población negra, en gran parte antiguos esclavos, accedió a la libertad y a la ciudadanía, desde luego que no fueron las mismas en que llegaron los blancos ${ }^{4}$.

Por eso mismo, en este trabajo quiero estudiar cuáles eran las principales características demográficas y sociales de la población de Cuba en el momento histórico que significa la eliminación del colonialismo español, de una manera dual. Es decir, de la sociedad negra y blanca, ya que ello conducirá a varias conclusiones que nunca se comprendería sin analizar la dialéctica racial confirmante de la historia de Cuba.

Para el examen de los caracteres demográficos y sociales enunciados utlizaré como fuente el Informe sobre el Censo de Cuba, 1899, Departamento de Guerra. Estados Unidos de América, Washington, 1900. Como su propio nombre indica, es una obra que hace referencia al censo mandado levantar por las autoridades de ocupación norteamericanas. El expresado informe, por la rigurosidad con que fue realizado el censo, ofrece una serie de datos que pueden aceptarse con seguridad.

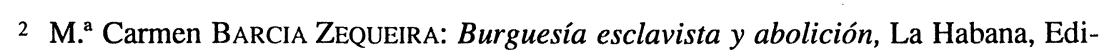
torial de Ciencias Sociales, 1987.

3 Manuel Moreno Fraginals: El Ingenio, 3 tomos, La Habana, Editorial de Ciencias Sociales, 1978. Rebeca ScotT: La emancipación de los esclavos en Cuba, México, Fondo de Cultura Económica, 1989.

4 Consuelo NARANJo y Armando García GonZÁlez: Racismo e inmigración en Cuba en el siglo XIX, Aranjuez, Madrid, Ed. Doce Calles, 1996.

R. I., 1998, n. $^{\circ} 212$ 
En suma, el propio gobierno norteamericano quería la mayor exactitud posible en el censo para así conocer la realidad social del territorio que controlaba. Hecho éste que mejor asegura su fiabilidad.

CARACTERES GENERALES DE LA POBlación. El IMPACTO DE LA GUERRA

En 1898 la población de Cuba era de 1.572.797 habitantes, divididos en 1.052.397 blancos y 520.400 de color. De todos ellos habían nacido en el exterior, 172.535 de los cuales 142.153 eran blancos, 129.240 españoles, el $75 \%$ de los extranjeros, y 30.382 de color, divididos en 14.614 chinos y 15.768 negros y mulatos de origen foráneo. Entre éstos, 12.953 se censaron como procedentes de África y no como cubanos. Ellos fueron los últimos esclavos que vinieron de ese continente y que al ser liberados quisieron seguir conservando su nacionalidad. Algo, desde luego, muy representativo y elocuente de la dignidad de una raza. En porcentajes, por grupos de población, la Isla estaba conformada por un $58 \%$ de población blanca, $17 \%$ de mulatos, $15 \%$ negros, todos ellos criollos. El $9 \%$ eran emigrantes, blancos y negros y el $1 \%$ chinos.

Por sexos, 815.205 varones y 757.292 hembras. En la población blanca los varones representaban el 54,1\% y las hembras el 45,9. Entre los de color, el 47,6 y el 52,4\%. Esto último se debe poner en relación con la eliminación de la trata, que ya es sabido proporcionaba fundamentalmente un aporte de varones y con el hecho de la mayor supervivencia de las mujeres entre los esclavos por tener un menor índice de mortandad, debido a razones de dedicación laboral.

La gráfica 1 presenta la composición cubana por lugar de nacimiento y sexo. En ella queda evidente cómo la población emigrante, por razones de dedicación laboral, base de su llegada a tierras cubanas, es fundamentalmente masculina. En el caso de la procedente de África, antiguos esclavos, se hacía notar la preferencia que siempre se tuvo en comprar varones por razones de efectiv lad y rentabilidad productiva.

En cuanto a la división por sexo y edad, las gráficas 2,3 y 4 muestran tanto en el caso de la población general como en las específicas de blancos y de color, una fuerte proporción de edades jóvenes. Y así resulta que el 80,3 de la población de Cuba, en su con- 
junto, tiene menos de 41 años, siendo la edad media de 20,7 años. Esto indica una enorme potencialidad poblacional medida tanto en términos demográficos como laborales.

Sin embargo, las citadas gráficas muestran las diferencias entre blancos y de color. La de estos últimos, presenta una serie de características que tienen mucho que ver con su pasado esclavo. Ello se hace notar en las edades más avanzadas, población que sufrió la esclavitud y, en consecuencia, se observa cómo la proporción de varones es mayor, así como hay una disminución cuantitativa notable en aquellos tramos de edad que por esos años estaban en edades más activas y que por tanto padecieron vitalmente más y por consiguiente tuvieron una mayor pérdida.

Otra característica común en ambas gráficas, de blancos y de color, es la fuerte reducción de población en los tramos hasta 4 años y el comprendido entre 21-24.

En ese tramo hasta 4 años, la población sólo representaba el $8,32 \%$ de la población total de Cuba, mientras el grupo de 5-9 ascendía al 14,38\%. Eso indica que el número de niños nacidos entre 1894-1899 en comparación con los que lo hicieron entre 1889 y 1894 fue mucho menor. Eso naturalmente tiene que ver con las circunstancias bélicas por las que atravesó la isla y que afectaron demográficamente de modo decisivo. también es significativa la reducción en el contingente de 21-24, puesto que en los años de guerra los jóvenes en armas sufrieron fuertes bajas. Esta característica demográfica lleva a observar los efectos de la guerra en la población cubana. Si se atiende al censo de 1887, la Isla contaba con 1.572 .000 personas. Es decir, que Cuba perdió entre ambos recuentos 58.890 habitantes. En el Informe del Censo de 1899 se lee: «Esta pérdida se puede atribuir a la reciente guerra civil y al sistema de reconcentración empleado en ella y los guarismos citados no expresan más que una parte de la pérdida debida a dichas causas. A juzgar por la historia de Isla y por el exceso de nacimientos sobre las defunciones, según está manifestado en los registros civiles, por defectuosos que éstos sean, es de creerse que la población aumentó desde el año de 1887 hasta principios de la guerra y que en dicha época ascendió a poco menos de 1.800 .000 habitantes. Es probable, pues, que las pérdidas, directas e indirectas, causadas por la guerra y el sistema de reconcentración, incluso la disminución en los nacimientos, en la 
inmigración y el aumento en las defunciones, ascendieron a un total aproximado de 200.000 almas. $\rangle^{5}$

La gráfica 5 muestra claramente cómo entre 1895 y 1898 hubo fuerte descenso en los nacimientos, lo cual va tanto en relación con la baja en los matrimonios, por las circunstancias propias de la guerra, y un aumento muy acusado en las defunciones. Un examen más pormenorizado señala que en los cuatro años sólo se registraron el $23,2 \%$ de los nacimientos efectuados en Cuba en los diez años de $1890-1899$, el 19,8\% de los matrimonios y el $60,6 \%$ de las defunciones. Esto da una idea patente de la fuerte incidencia de la guerra en la población de $\mathrm{Cuba}^{6}$.

\section{DISTRIBUCIÓN DE LA POBLACIÓN}

La isla de Cuba estaba dividida en seis provincias que abarcaban las siguientes superficies (en millas cuadradas), con diferente densidad de población.

\begin{tabular}{lrcc}
\hline PROVINCIA & ÁREA & POBLACIÓN & HAB. POR MILLA \\
\hline HABANA & 2772 & 424804 & 153 \\
MATANZAS & 3700 & 202444 & 55 \\
PINAR DEL RíO & 5000 & 173064 & 35 \\
PUERTO PRÍNCIPE & 10500 & 88234 & 8 \\
SANTA CLARA & 9560 & 356536 & 37 \\
SANTIAGO & 12468 & 327715 & 26 \\
\hline
\end{tabular}

Existían catorce ciudades con más de 8.000 habitantes: Habana, 235.981; Santiago de cuba, 43.090; Matanzas, 36.374; Cienfuegos, 30.038; Puerto Príncipe, 25.102; Cárdenas, 21.940; Manzanillo, 14.464; Guanabacoa, 13.965; Santa Clara, 13.763; Sagua la Grande,

5 Informe sobre el Censo de 1899, Departamento de Guerra, Washington, 1900, pp. 103. A este respecto, tengo que agradecer la información facilitada por el Dr. Francisco Pérez Guzmán, del Instituto de Historia de Cuba, que prepara una monografía sobre el impacto de la guerra sobre la población de Cuba.

6 Juan PÉREZ DE LA RIVA: Los recursos humanos de Cuba al comenzar el siglo: inmigración, economía y nacionalidad (1899-1906), México, en La República neocolonial. Anuario de Estudios Cubanos, Editorial de Ciencias Sociales, 1975, p. 23. 
12.728; Sancti Spíritus, 12.696; Regla, 11.363; Trinidad, 11.120; Pinar del Río, 8.880.

Sobresale La Habana, con una población que suponía el 15\% del total de la Isla y desde luego centro de la actividad política y financiera. Sin duda, para su época, una de las grandes megalópolis de América.

La Habana tenía prácticamente el mismo contingente poblacional, escasamente menor, que el conjunto de las otras trece ciudades cubanas con más de 8.000 habitantes. Eso sólo da idea de la importancia poblacional de la capital habanera.

En cuanto a la distribución racial, la gráfica 6 expresa claramente esa situación, siendo Matanzas, por razones de índole productiva, y Santiago, por causas poblacionales, las provincias con mayor número de elementos de color ${ }^{7}$. Aquellas zonas donde estuvieron concentradas la mayor parte de las tierras dedicadas al cultivo azucarero (caso de Matanzas), recibieron abundante contingente de esclavos que después de su liberación quedaron viviendo en esos mismos lugares. Ocurre lo mismo con la población china. En cambio, en las áreas donde se desarrollaron otro tipo de actividades agrícolas hubo menos necesidad de importar negros. Esa situación provocó el «blanqueamiento» o «ennegrecimiento» de esas provincias. El caso de Santiago, repito, tiene motivos más poblacionales, como explicaré más adelante. En cuanto a La Habana, el predominio blanco es debido, fundamentalmente, a la dedicación mercantil, administrativa y militar de ciudad Habana, y por ello centro elegido por los emigrantes blancos y de las clases profesionales criollas, la mayoría de los cuales eran blancos.

La gráfica 7 presenta la división proporcional por provincias de grupos de población. En ella queda evidenciado cómo los blancos criollos predominan, fundamentalmente, en Puerto Príncipe y en Pinar del Río y Santa Clara, siendo Matanzas y Santiago, las menos pobladas por blancos nacidos en el país.

Los emigrantes, sobre todo españoles como ya expresé, se radican en La Habana por las razones aducidas. De los españoles que vivían en Cuba, casi la mitad lo hacían en La Habana, un total de 61.426 personas, seguida de Santa Clara, donde residían 28.366 de

\footnotetext{
7 Pablo TORNERO: Crecimiento económico y transformaciones sociales. Esclavos, hacendados y comerciantes en la Cuba colonial, Madrid, Ed. Ministerio de Trabajo, 1996.
} 
ellos. Los negros estaban afincados sobre todo en Matanzas y en menor número en Pinar del Río y Santiago, registrando Puerto Príncipe la menor proporción de negros entre sus habitantes.

Por su parte los mulatos (mestizos como expresa el texto analizado) son mayoritarios proporcionalmente en Santiago. De hecho es este segmento racial el que «ennegrece» la provincia y el que le da su más amplio contenido cultural, desde un punto de vista racial. De ahí que la importante presencia de la población de color en esta provincia se deba más a razones demográficas y sociales que al pasado productivo de su territorio, como sucedió en el área matancera. Es importante la proporción de mulatos en Matanzas y Santa Clara, ocupando Pinar del Río el último lugar en ciudadanos de este grupo poblacional.

Por fin, los chinos, aunque minoritaria tienen presencia en Matanzas y Santa Clara, siendo prácticamente nula su participación en el resto de Cuba.

Un examen por localidades y provincias, en cuanto a la división racial, ofrece los siguientes datos: en La Habana todas las localidades cuentan con mayoría blanca, lo mismo que sucede en Santa Clara y Puerto Príncipe. En Matanzas sí se encuentran focos con predominio negro y mulato: Carlos Rojas con un 57\% de población de color; Guaracaro, 50\%; Jovellanos, 56,9\%; Macuriges, 54,8\%; Martí, 50,5\%; Máximo Gómez, 52,4\%; Palmillas, 50,8\%; Perico, 56,9\%; San José de los Ramos, 51,4\%.

Lo mismo ocurre en Pinar del Río, donde el elemento de color es el más importante en algunos territorios, como Bahía Honda, con un 51,1\%; San Diego de Núñez, 55,7\%, y Cabañas, con 62,0\%.

En Santiago es donde se encuentra la única ciudad importante de la isla, Santiago de Cuba, con más alto volumen de personas de color, el $56,6 \%$. También en esta provincia están radicados los núcleos de mayor proporción negra y mulata de todo el territorio cubano, caso del Cobre, con 76,7\%; Alto Songo, 74,9\%; San Luis, 70,6\%; Guantánamo, 68\%, y ya en menor porcentaje Baracoa, 54,4\%; Caney, $52,8 \%$ y Cristo, $50,9 \%$.

En cuanto a la división campo-ciudad, el total de la población cubana estaba distribuida entre 491.504 habitantes de zonas urbanas, es decir en ciudades de más de 8.000 habitantes y 1.081.293 en zonas rurales. En términos proporcionales, un $32 \%$ residía en ciudades, prácticamente la mitad en La Habana, como ya se comentó, y un 
$68 \%$ en el medio rural. Esto lleva a hablar claramente de la sociedad cubana como eminentemente rural, con todo lo que ello supone.

Por razas, la población urbana y rural se distribuye según las siguientes proporciones:

\begin{tabular}{|l|c|c|}
\cline { 2 - 3 } \multicolumn{1}{c|}{} & \% BLANCOS & \% DE COLOR \\
\hline Ciudad Habana & 72,4 & 28,6 \\
Trece otras ciudades & 62,6 & 37,4 \\
Distritos rurales & 67,0 & 33,0 \\
\hline
\end{tabular}

Es decir, para el conjunto de la Isla, la más alta proporción de blancos se encuentran en La Habana y en los distritos rurales, mientras la población de color se distribuye sobre todo en distritos urbanos.

Un examen por provincias lleva a la misma conclusión:

\begin{tabular}{|lcccc|}
\cline { 2 - 5 } \multicolumn{1}{c|}{} & \multicolumn{2}{c|}{ BLANCOS } & \multicolumn{2}{c|}{ COLOR } \\
\hline PROVINCIAS & D. URBANOS & D. RURALES & D. URBANOS & D. RURALES \\
Habana & 71,6 & 76,9 & 28,4 & 23,1 \\
Matanzas & 66,3 & 55,1 & 33,7 & 44,9 \\
Pinar del Río & 66,8 & 73,0 & 33,2 & 27,2 \\
Puerto Príncipe & 70,9 & 83,2 & 29,1 & 46,8 \\
Santa Clara & 63,3 & 70,2 & 36,7 & 29,8 \\
Santiago & 48,6 & 56,7 & 51,4 & 43,3 \\
\hline
\end{tabular}

En todas las provincias, excepto Matanzas, por razones de índole productiva ya comentadas, y Puerto Príncipe, por su falta de posibilidades para la integración en su contexto económico, mulatos y negros se establecen en zonas urbanas. Lo contrario sucede con los blancos. Esta presencia destacada en las ciudades es consecuencia directa de dos factores: el escaso margen de acceso a la propiedad y explotación de la tierra y el pasado laboral. Al primer factor me referiré más adelante. En cuanto al segundo, hay que decir que explotado sin límites, tanto por su condición de esclavo como por el trabajo rural en ingenios o centrales, o en cualquier otra actividad agraria, el hombre de color ve en la agricultura, en el trabajo campesino, dolor, humillación y pobreza. Todo aquello le recuerda su explotación y busca en la ciudad tanto un lugar donde olvidar su pasado como un 
sitio donde encontrar la posibilidad de cambiar su tradicional destino. Por otro lado, el antiguo esclavo, ahora convertido en proletario, es demandado como mano de obra barata y eficaz en las zonas urbanas, ya que su trabajo puede ser adquirido en condiciones más ventajosas que las exigidas a los blancos.

\section{INSTRUCCIÓN Y SOCIEDAD}

Entre los habitantes de Cuba el grado de instrucción era el siguiente:

No sabe leer

1.004 .884

Saber leer pero no escribir .......... 33.003

Sabe escribir ............................. 514.340

Instrucción superior .................. 19.158

No contestó ............................... 1.412

Es decir, un $63,9 \%$ eran analfabetos, un $2,1 \%$ semianalfabetos, el $32,7 \%$ estaban alfabetizados y sólo el $1,2 \%$ tenía formación superior $^{8}$.

Por provincias la proporción de alfabetizados era igualmente muy baja:

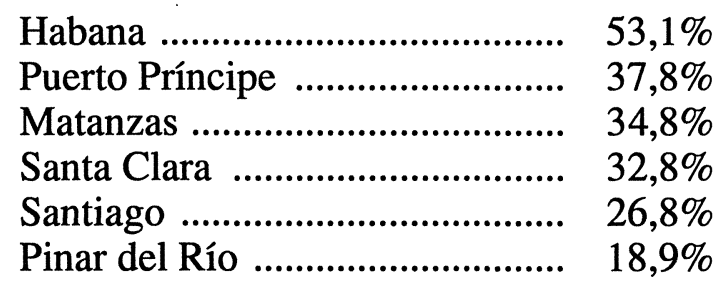

Excepto en el caso de la provincia habanera, y ello por contar en su proporción la capital, no hay ninguna provincia que llegue siquiera a que la mitad de su población esté alfabetizada.

8 Jorge IBARRA: Nación y cultura nacional, La Habana, Editorial Letras Cubanas, 1981. Francisco LÓPEZ SEGRERA: Cuba: cultura y sociedad, La Habana, Ed. Letras Cubanas, 1989.

R. I., 1998, n. $^{\circ} 212$ 
Si se analiza esta cuestión en términos urbanos y rurales, las proporciones de alfabetizados se presentan así:

Ciudad Habana ......................... $\quad 65,9 \%$

Trece otras ciudades ................ 57,6\%

Resto Cuba ............................. 24,4\%

Es pues más que evidente la supremacía de las ciudades en cuanto a grado de instrucción en Cuba. Ello patentiza que era en el marco urbano donde se registraba una mayor proporción de personas alfabetizadas de la isla, como ofrecen las siguientes cifras:

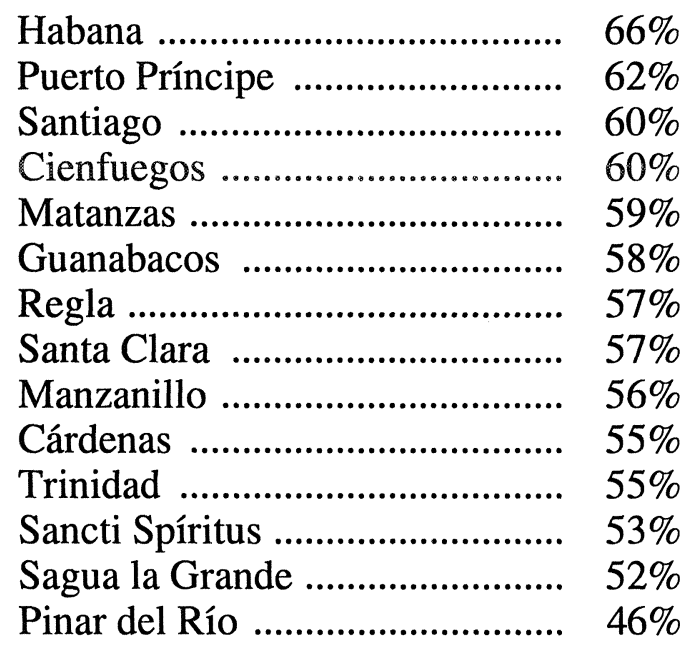

Por su parte, los residentes en las zonas rurales ofrecían una proporción de alfabetizados bastante más baja:

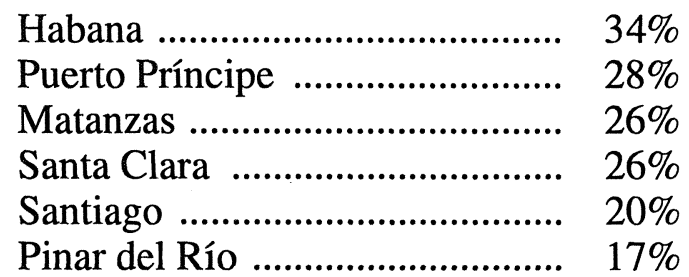

En definitiva, de todo lo expuesto se deduce la enorme falta de formación del pueblo de Cuba producto de una política educativa

R. I., $1998, \mathrm{n}^{\circ} 212$ 
nefasta, llevada a cabo tanto por las autoridades metropolitanas como por la propia oligarquía criolla. En el fondo ello formaba parte del propio mecanismo de explotación colonial. Como consecuencia, la inmensa mayoría de los cubanos llegó a la emancipación de España en condiciones muy deplorables en lo referente al grado de instrucción, con todas las consecuencias sociales que de ello se derivan.

Del mismo modo se hace evidente cómo esa situación se hace muy notoria en el medio rural. Ello da idea de la poca atención recibida por el sector campesino que no sólo en este aspecto educativo se vio muy marginado frente a los grupos urbanos. Por ello mismo queda patente cómo el colonialismo español, además de prestar una muy escasa atención a la formación cultural y por consiguiente dejar a la sociedad cubana desarmada, en este sentido, frente a la nueva etapa que se inaguraba, provocó con la diferencia en el grado de instrucción una mayor separación entre campo-ciudad en Cuba. Separación en gran parte buscada y dirigida por los núcleos dirigentes como una forma de colonialismo interior y que también incidía en la desigualdad regional. En consecuencia se aprovechó esa diferencia educativa entre los distintos espacios cubanos para acrecentar el desarrollo desigual.

Esta falta de preparación se hace más notoria si se busca el número de personas con instrucción superior. De un total de 290.905 personas que componían los ciudadanos cubanos mayores de 21 años, sólo 8.861, el 3\%, tenían estudios superiores.

Dicho esto es fácil de entender que la herencia colonial recibida por Cuba, en el orden cultural, no le era precisamente de ayuda para el resto del futuro. Excepto en el caso de determinados núcleos urbanos, sobre todo La Habana, el grado de preparación educativa era mínimo. Así se comprende mejor que a la sociedad cubana le fuera difícil cambiar, con sus propias fuerzas, los destinos del país.

Esta situación es más acusada si se examina la cuestión desde un punto de vista racial. El 51\% de los blancos criollos no sabían leer, entre los de color el nivel de analfabetos llegaba al 74\%.

En la misma ciudad de La Habana, donde era menor el nivel de analfabetos, entre los blancos la proporción de éstos era sólo del 11\%; sin embargo, los de color registraban una proporción del $45 \%$. En Matanzas, los de color tenían un $86 \%$ de analfabetos frente al $45 \%$ de los blancos. 
En cuanto a formación superior, los ciudadanos blancos que contaban con esta titulación eran sólo 14.065, los de color ascendían a la ínfima cantidad de 515 .

Con el análisis de esos datos es perfectamente válido decir que las enormes diferencias existentes entre blancos y de color hacían imposible que ambos grupos tuviesen las mismas oportunidades de acceso al universo social cubano. En definitiva, como también expondré más adelante, la muy escasa preparación del colectivo de color era una forma de control social de este grupo por parte de la oligarquía criolla blanca. Igualmente, en este caso el racismo se hacía patente y se desarrollaba.

La gráfica 8 explica los grados de instrucción entre los distintos grupos de población en Cuba mayores de 21 años. Es decir, aquellas personas con mayor capacidad de integración en el mercado laboral, sobre todo en el más cualificado. En ella queda evidenciado cómo la población blanca criolla presenta rasgos de formación cultural más avanzados que los de color, como ya he repetido, aunque son los emigrantes españoles y sobre todo los propios de otros países los que tienen un porcentaje de instrucción superior. Por consiguiente, el grupo blanco, en principio, tenía más posibilidades de desarrollo personal y social que el de color y por tanto ambos grupos emergían de modo bien diferente a la nueva etapa de la historia de Cuba. De todos modos, por su mayor potencialidad educacional, parece que aquellos sectores en los que se exigía un mayor grado de instrucción, la presencia de emigrantes era notoria. En última instancia era otra manera de seguir colonizando al país.

\section{ACTIVIDAD LABORAL Y OCUPACIONAL}

En la población de Cuba las personas dedicadas a una ocupación lucrativa representaban el $41,2 \%$. Por sexos, el 68,2\% de los hombres y el 8,9\% de las mujeres. Entre las personas en edad activa, varones y hembras mayores de diez años, por provincias, la proporción de habitantes con ocupación se conformaba del modo siguiente:

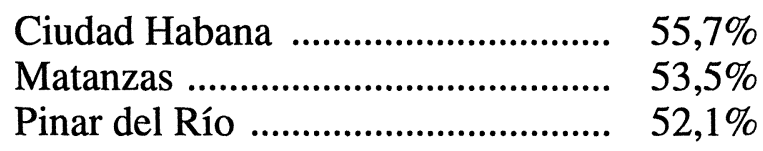

R. I., 1998, n. ${ }^{\circ} 212$ 


\begin{tabular}{|c|c|}
\hline Santa Clara & $51,8 \%$ \\
\hline Habana (excluyendo la ciudad) ....... & $50,2 \%$ \\
\hline Puerto Príncipe . & $49,9 \%$ \\
\hline Santiago ............... & 45 \\
\hline
\end{tabular}

El espacio de Cuba, con una mayor tasa ocupacional es naturalmente la capital habanera, foco principal de la actividad mercantil, industrial y financiera de la isla. También la región de Matanzas, centro de la producción azucarera.

En el censo analizado, la población trabajadora viene distribuida en cinco grandes apartados: agricultores, pescadores y mineros (sector primario), manufacturas e industria (secundario), comercio y transportes, servicios profesionales y servicio doméstico (servicios).

La gráfica 9 presenta la proporción de estos grupos de profesiones por sexos. Entre los varones, la mayor parte de ellos estaba ocupada en el sector primario. El porcentaje de empleados en la industria era muy corto e ínfimo el dedicado a servicios profesionales. En cambio llama la atención los empleados en el servicio doméstico, trabajo en el cual estaban la mayoría de las mujeres que sin embargo, porcentualmente, son más numerosas que los hombres en la industria. Esto es algo que tiene mucho que ver con el laboreo femenino en las manufacturas tabaqueras ${ }^{9}$.

En definitiva, este cuadro ocupacional es el propio de un país con una estructura económica de base primaria, tradicional, y por consiguiente colonizado por otras economías de signo industrial, sobre todo la de Estados Unidos, que utilizaron al tejido productor cubano y conformaron su lugar en el mercado internacional ${ }^{10}$.

En la gráfica 10, los grupos profesionales señalados están irregularmente distribuidos por provincias, mostrando así la especificidad de cada una de ellas y dejando patente el desarrollo desigual en el país.

La región habanera, sobre todo por la influencia de la capital, es la que tiene la menor proporción del sector primario y la mayor en los sectores secundarios, sobre todo el industrial, lo cual lleva a en-

\footnotetext{
9 María POUMIER: La vida cotidiana en Cuba en 1898, La Habana, Editorial de Ciencias Sociales, 1975, y Jean STUBBS: Tobacco on the Periphery: A case study in Cuban Labour History, 1860-1958, Cambridge, University Press, 1985.

10 Óscar ZANETTI LECUONA: Los cautivos de la reciprocidad, La Habana, Ed. Enpes, 1989.
} 
tender que es esta región la que engloba más número de manufacturas y de servicios. También es aquí donde comerciantes y transportistas se concentran. La capital habanera es determinante en este sentido, al igual que para entender la alta proporción de sirvientes. Matanzas y Santiago, quizás, responden de manera más global al contexto ocupacional general de la isla. Una fuerte proporción en el sector agrícola que es mínimamente apoyado por un núcleo comercial y que tiene también una corta base manufacturera.

Por contra, Pinar del Río es la provincia con una estructura ocupacional más elemental que refleja su primitivo sistema productivo.

En cuanto al examen de este aspecto desde la óptica racial, consta una mayor proporción de personas ocupadas entre los de color, el $42,1 \%$ del total, que los blancos, de los cuales trabajan el 38,3\%.

Por sexos y razas, la población laboral registra los siguientes porcentajes:

\begin{tabular}{|c|c|}
\hline Varones blancos & $68,4 \%$ \\
\hline Varones de color & $67,2 \%$ \\
\hline Hembras blancas & $6 \%$ \\
\hline Hembras c & 18,2 \\
\hline
\end{tabular}

Es clara la predominancia ocupacional entre las hembras de color, mientras que entre los varones, tanto blancos como de color, la proporción es muy parecida entre hombres y mujeres.

La gráfica 11 ofrece el porcentaje de ocupación en determinadas profesiones por grupos de población (AL. Albañiles, CP. Carpinteros, CA. Cantineros, CO. Comerciantes, CR. Criados, JO. Jornaleros, LA. Lavanderos, MA. Marineros y Barqueros, PA. Panaderos, TA. Tabaqueros, VE. Vendedores de mercancías, ZA. Zapateros) y queda patente cómo la mayor parte de los oficios estaban desempeñados en la Isla por personas de color, sobre todo albañiles, carpinteros, panaderos y zapateros. Lo mismo sucede en otras ocupaciones como criados y lavanderas, donde las mujeres tienen su principal actividad. Así entre 22.807 mujeres censadas como criadas, 17.390 son de color. Igual ocurre con las lavanderas, entre las cuales hay 17.555 de un conjunto total de 20.980. Los blancos predominan entre jornaleros y tabaqueros, mientras los emigrantes sobresalen entre cantineros, marineros y vendedores al por menor.

R. I., 1998, n. $^{\circ} 212$ 
Esta dedicación de los ciudadanos de color a determinados oficios es algo que se relaciona con el predominio de mulatos y negros en los núcleos urbanos, por las razones que anteriormente comenté. Hay en este sentido también que comentar que este hecho se deriva de su escaso acceso al uso y propiedad de la tierra. Así, en el censo analizado se escribe que de las 60.710 fincas de labor que había en Cuba, un 22,9\% las poseían blancos y un $49 \%$ las tenían arrendadas blancos, haciendo un total de $71,9 \%$ las ocupadas por éstos. La población de color poseía un 5,1\% y arrendaban un 18,5\% que hacían un total de $23,6 \%{ }^{11}$.

De las áreas cultivadas de las fincas de labor en Cuba, un 40,7\% las poseían blancos y un $42,2 \%$ las arrendaban también blancos, es decir, el $84,9 \%$ de esa superficie. Los de color sólo poseían un 2,8\% y arrendaba un $8,2 \%$, haciendo así un total de un $11 \%$ y arrendaba un $8,2 \%$. Además, las fincas más fértiles y dedicadas a cultivos más rentables, por supuesto estaban en su gran mayoría en manos de blancos. Todo ello era otra manera de segregación social, máxime si se piensa que la propiedad de la tierra era para esta época una de las maneras más sólidas de integración en el país que cualquier grupo humano tenía. Ésto explica, lógicamente, el que los ciudadanos de color tuviesen que derivar sus actividades hacia otros objetivos. Pero también influye en esta huida de actividades agrícolas, de hecho el mayor porcentaje de jornaleros en Cuba lo ofrece el componente blanco, otro factor al que ya me referí, como es el que la tierra era para las gentes de color sinónimo secular de humillación y explotación. También esta cuestión tiene que ver con el hecho de que tradicionalmente en Cuba estos oficios eran tareas de libres de color o esclavos alquilados por sus amos, por el hecho de que los blancos no se ocupaban en ellas.

Por otro lado, las labores urbanas menos cualificadas, como lavanderas o criados/das, estaban en muy alta proporción en manos del grupo de color. De hecho, eran trabajos «de negros» y es que, observando la gráfica 12, queda patente cómo entre las ocupaciones más cualificadas la presencia del grupo de color es mínima (AB. Abogados, AC. Actores, AR. Arquitectos, ART. Artistas, BA. Banqueros, CL. Clérigos, FU. Funcionarios, HA. Hacendados, L.H.C.

11 Fé IGLESIAS: “La tierra de Cuba y Puerto Rico en 1899”, Ibero-Americana Pragensia, Supplementum 5/1991, pp. 125-144. 
Literatos y hombres ciencia, MA. Maestros, ME. Médicos, MU. Músicos, PE. Periodistas, VE. Vendedores). Sólo entre actores y músicos es importante el porcentaje de color. Es bien sabido que en sociedades racistas, estas ocupaciones permiten a las minorías marginadas alcanzar un determinado estatus social. Hay que destacar la presencia de los emigrantes entre artistas, banqueros y vendedores al por mayor, mientras los profesionales liberales como abogados, funcionarios y médicos están en manos de blancos criollos.

En este sentido, la integración del grupo de color en la sociedad civil cubana se realizó casi siempre en tareas marginales urbanas, producto naturalmente tanto de su preferente ubicación en las ciudades como de su escaso grado de instrucción académica. Ello lleva a decir que existió un fuerte control social para marginar al grupo de color dentro de actividades que tuviesen escasa repercusión intelectual o económica sobre el conjunto de la sociedad cubana. Esa integración marginal resultado de una política colonial racista y que al tiempo tiene mucho que ver con el pasado productivo esclavista del colectivo de color, situó a este grupo a principios del siglo $\mathrm{XX}$ en claras condiciones de inferioridad para desarrollar su futuro. En definitiva, fue una integración racista en una sociedad racista. Los antiguos esclavos o incluso los de color libres por el peso de su historia y por los condicionantes a los que fueron obligados tendrían que esperar muchos años para que su condición humana fuese considerada paritariamente a la de los blancos en la sociedad cubana.

The author discusses the demographic structure and nature of Cuban society in the late 19th-century on the basis of the census of 1899. He argues that the strongly marked social differentiation in Cuba at the time, the duality in its social order of whites $v$. blacks, was grounded in the prevailing economic structure of the island and ultimately in the plantation economy. This situation conditioned the integration of the black population in Cuba's civil society in the first years of the new republic. 
COMPOSICIÓN DE LA POBLACIÓN CUBANA POR LUGAR DE NACIMIENTO Y SEXO

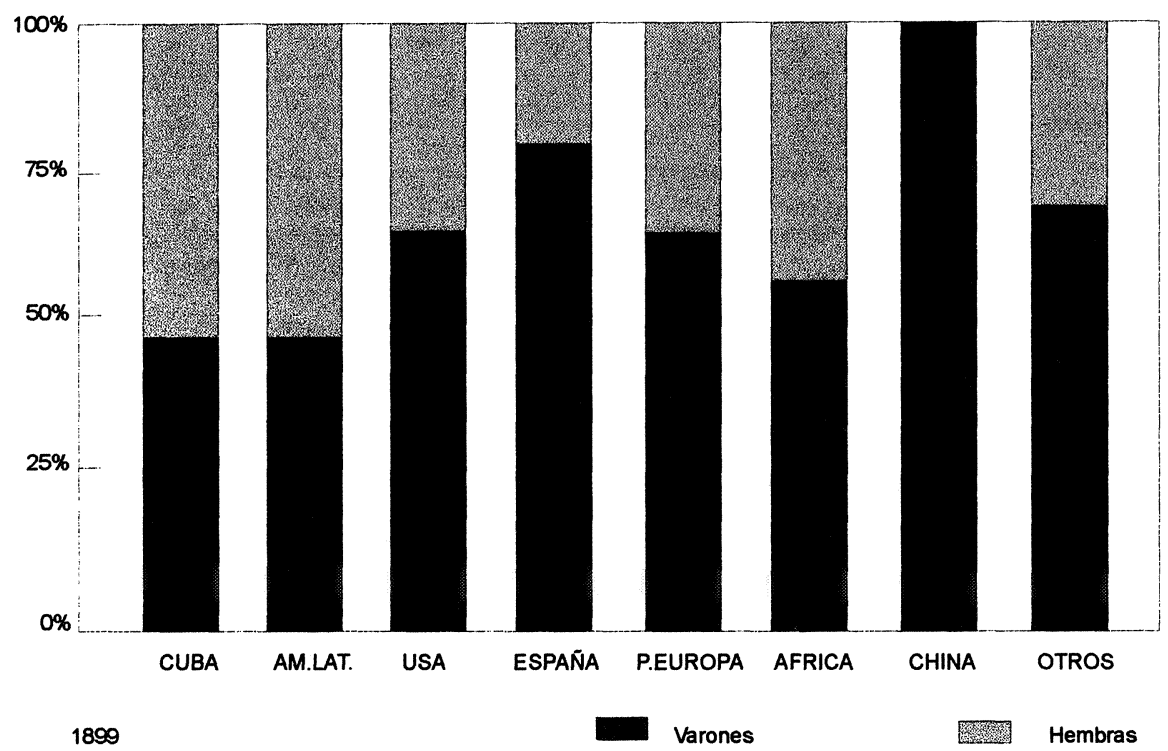

POBLACIÓN DE LA ISLA DE CUBA EDAD Y SEXO

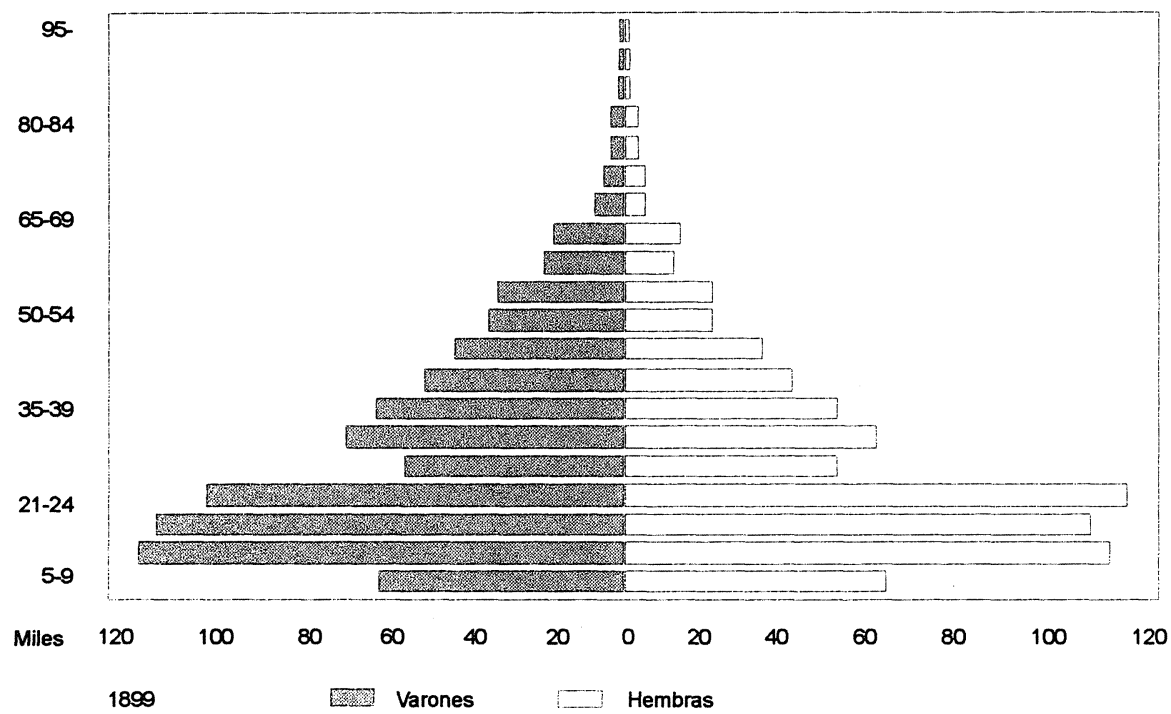

R.I., 1998, n. $^{\circ} 212$ 
POBLACIÓN BLANCA DE LA ISLA DE CUBA EDAD Y SEXO

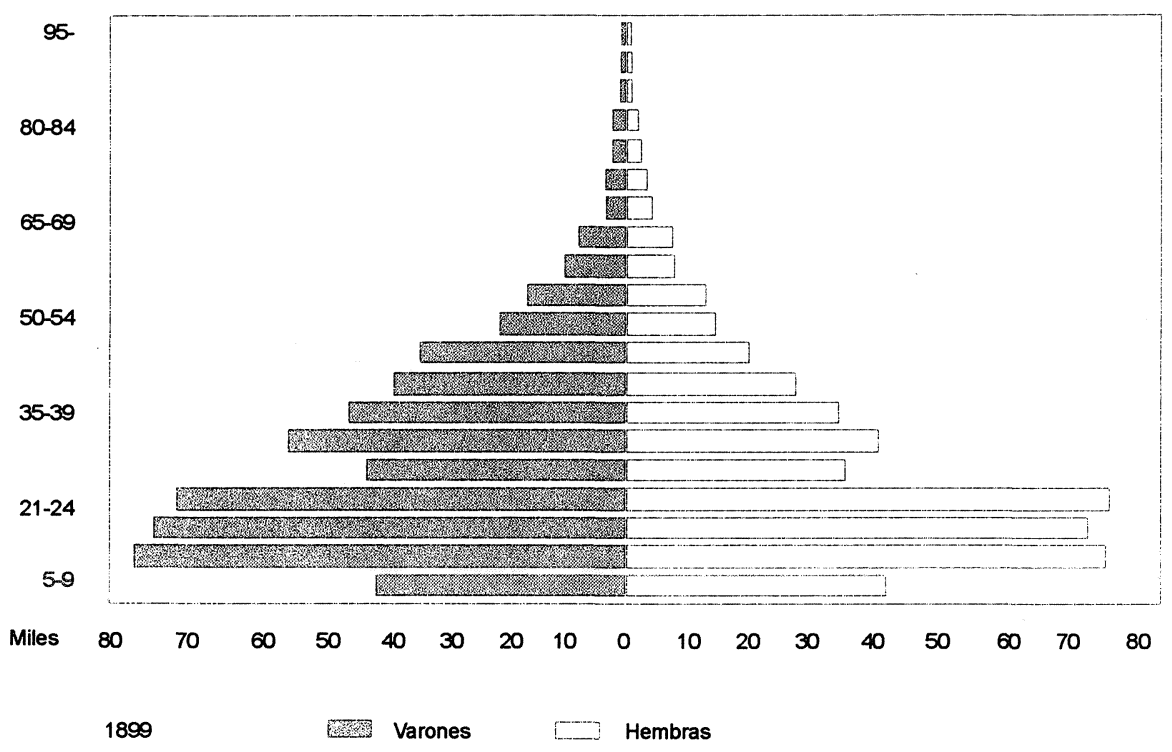

POBLACIÓN DE COLOR EN LA ISLA DE CUBA EDAD Y SEXO

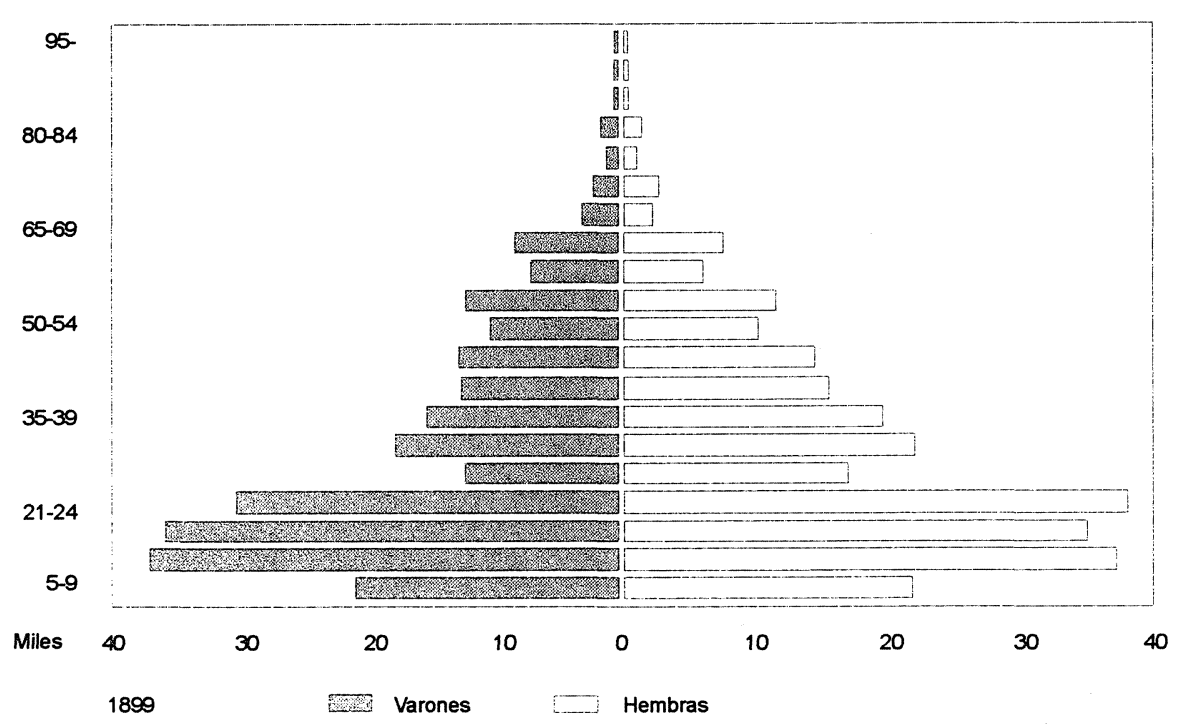

R. I., $1998, \mathrm{n}^{\circ} 212$ 
EVOLUCIÓN DE NACIMIENTOS, MATRIMONIOS Y DEFUNCIONES EN CUBA

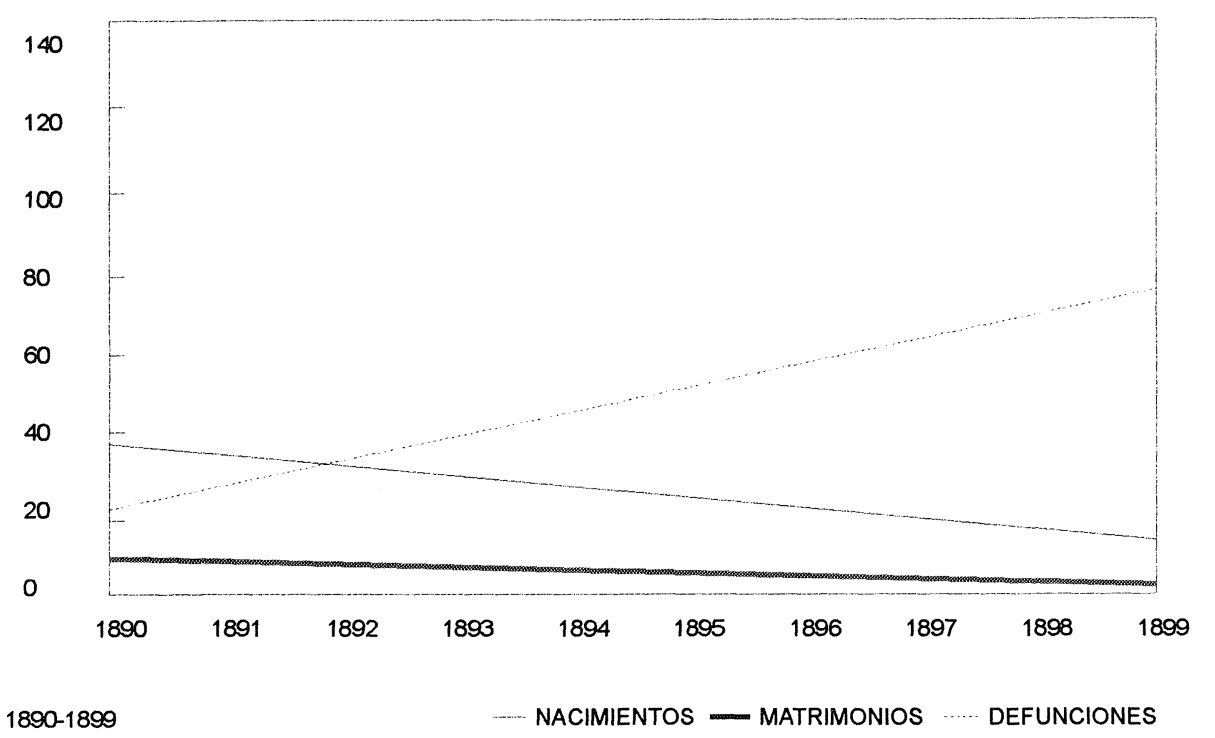

\section{PROPORCIÓN POR PROVINCIAS \\ DE GRUPOS DE POBLACIÓN}

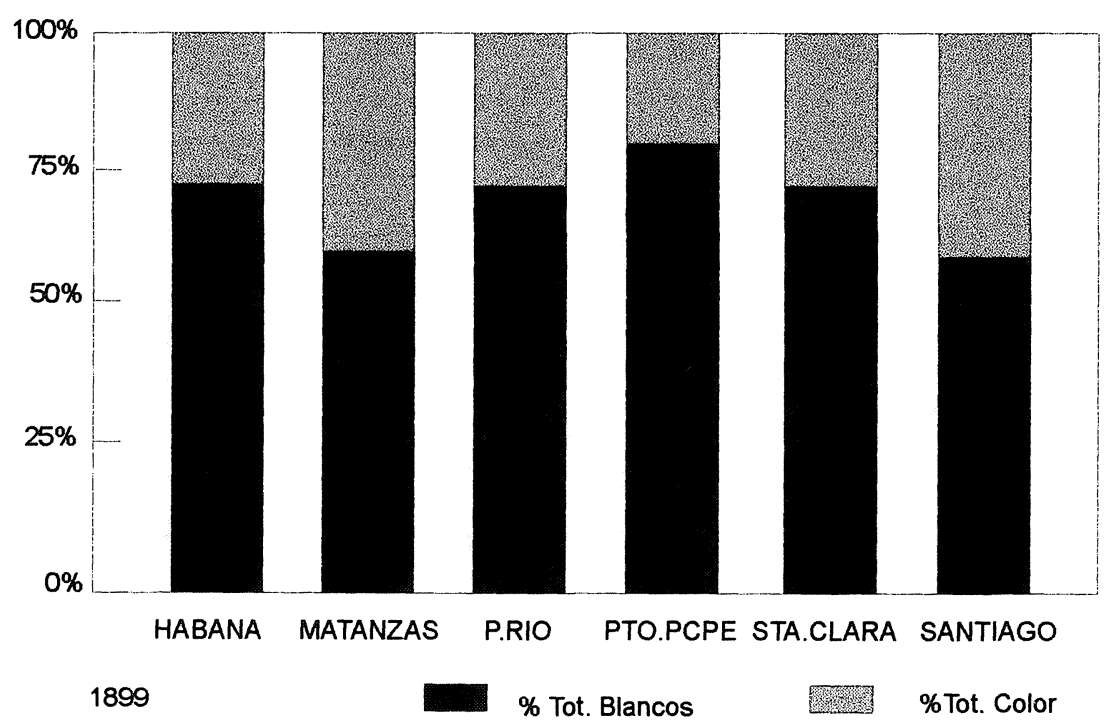

R.I., 1998, n. $^{\circ} 212$ 
PROPORCIÓN POR PROVINCIAS

DE GRUPOS DE POBLACIÓN

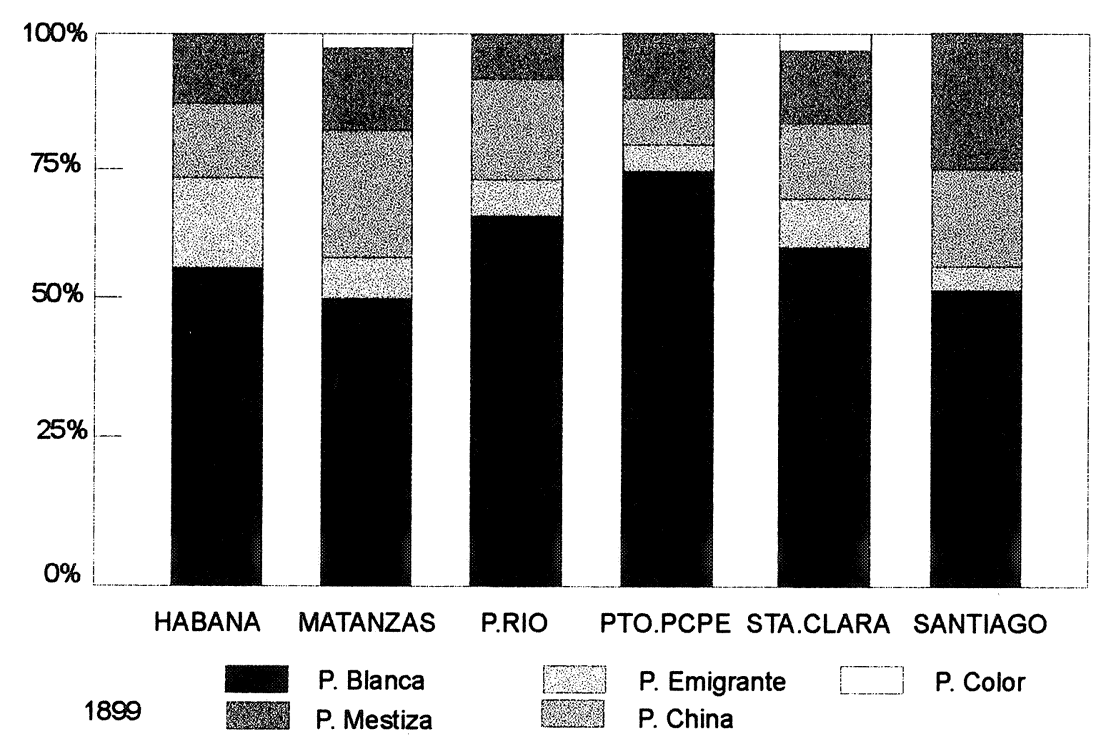

PROPORCIÓN POR PROVINCIAS

DE GRUPOS DE POBLACIÓN

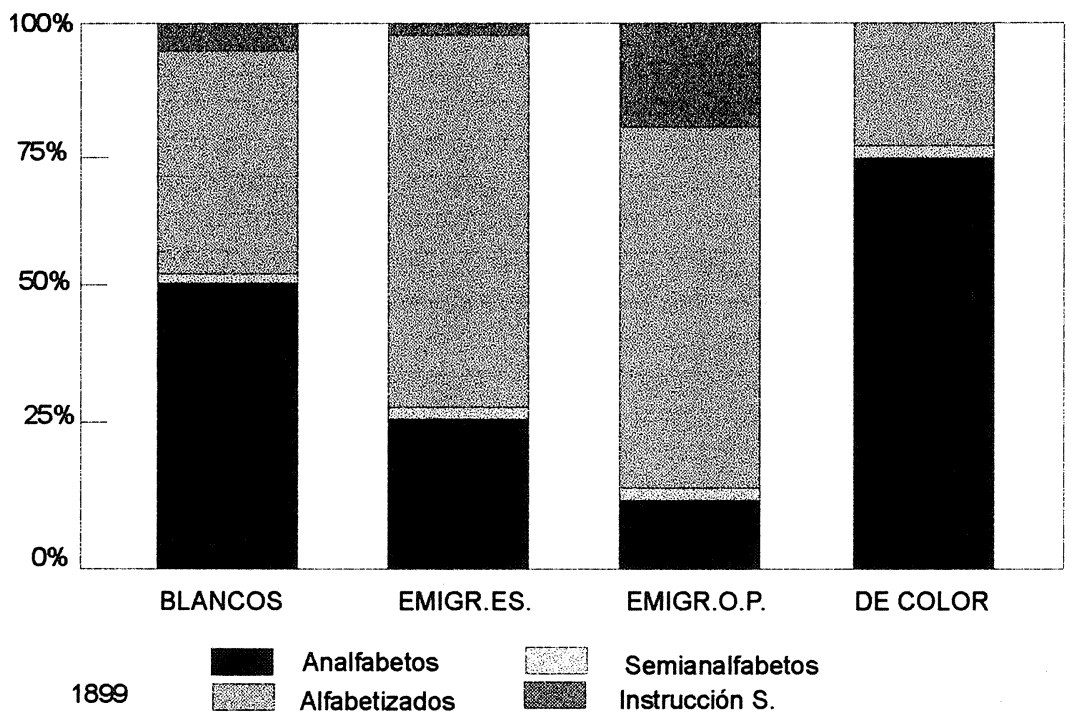

R. I., 1998, n. ${ }^{\circ} 212$ 


\section{PROPORCION POR PROVINCIAS} DE GRUPOS PROFESIONALES

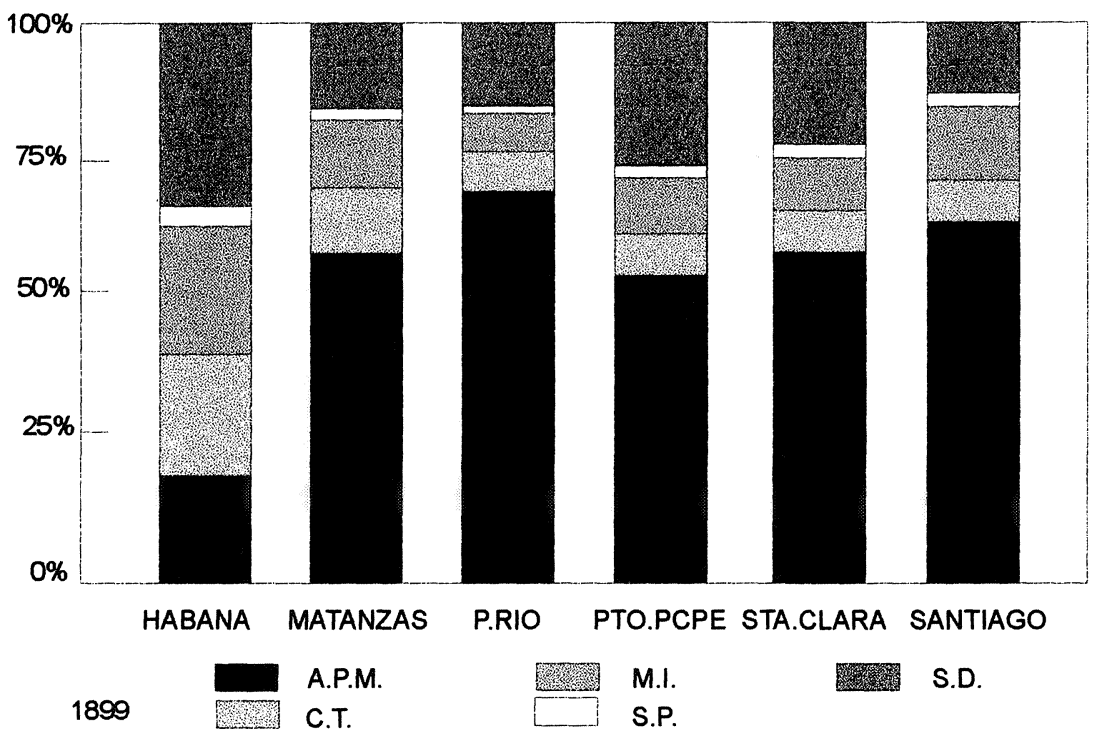

POBLACIÓN DE CUBA POR GRUPOS DE PROFESIONES Y SEXOS

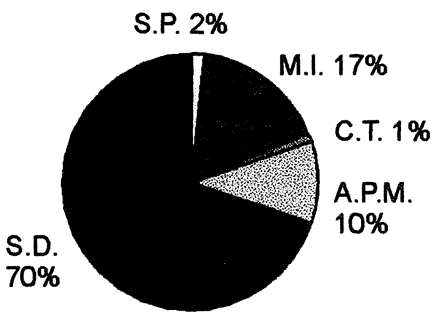

HEMBRAS

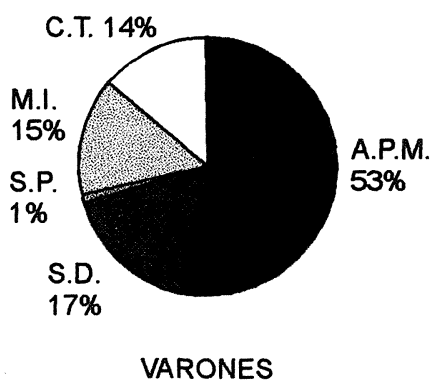

R. I., $1998, \mathrm{n}^{\circ} 212$ 
PROFESIONES Y GRUPOS DE POBLACIÓN EN CUBA

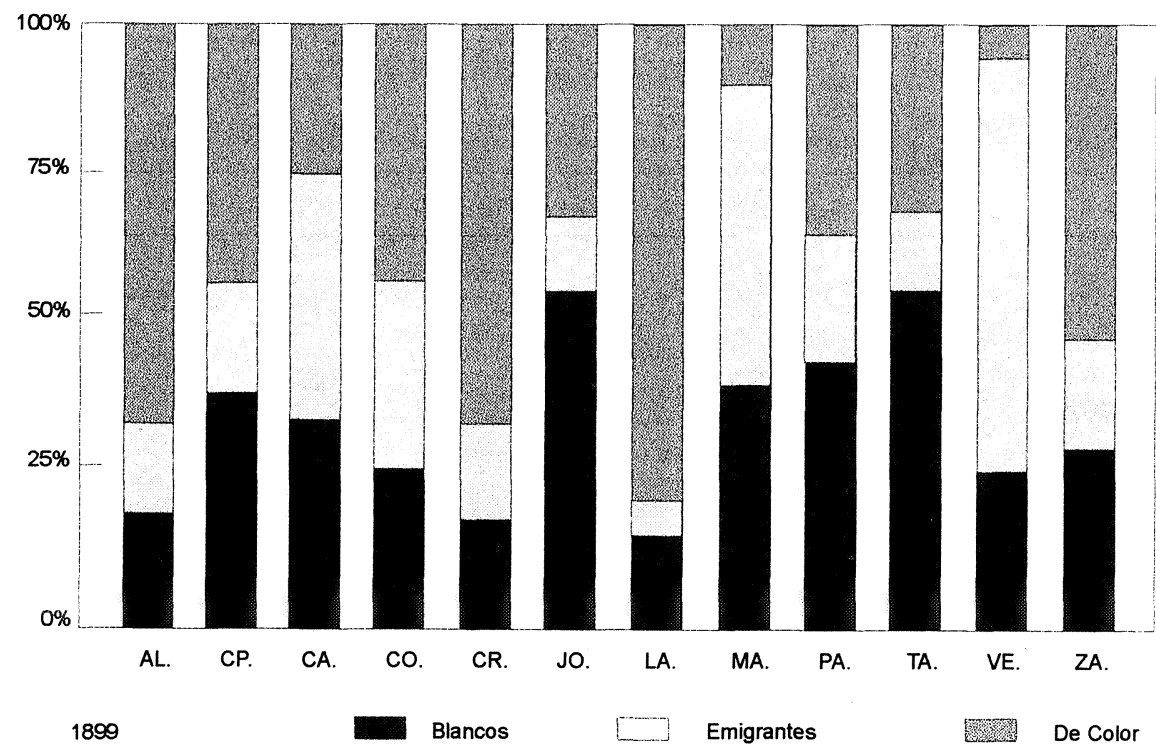

PROFESIONES Y GRUPOS DE POBLACIÓN EN CUBA

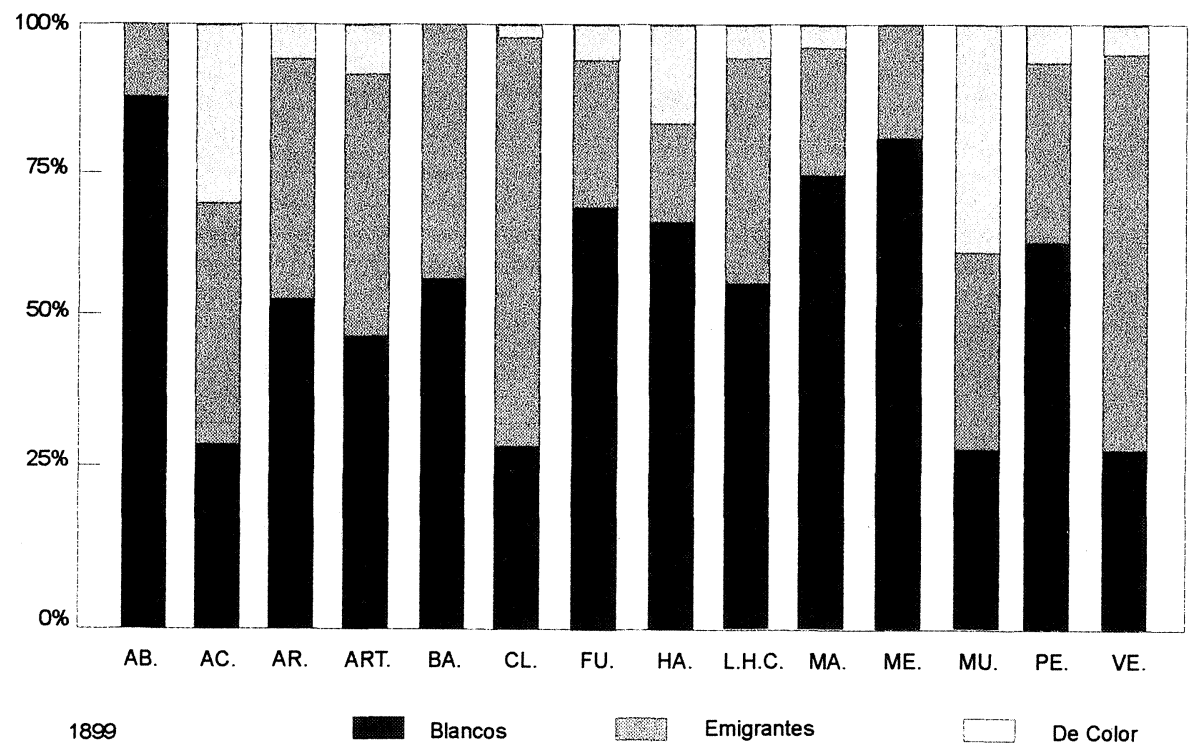

R.I., 1998, n. $^{\circ} 212$ 